\title{
Comprehensive learning particle swarm optimization for sizing and placement of distributed generation for network loss reduction
}

\author{
Eshan Karunarathne ${ }^{1}$, Jagadeesh Pasupuleti ${ }^{2}$, Janaka Ekanayake ${ }^{3}$, Dilini Almeida ${ }^{4}$ \\ ${ }^{1,2,3}$ Institute of Sustainable Energy (ISE), Universiti Tenaga Nasional (UNITEN), Malaysia \\ ${ }^{4}$ Department of Electrical Engineering, University of Peradeniya, Sri Lanka
}

\begin{abstract}
Article Info
\section{Article history:}

Received Feb 3, 2020

Revised Apr 4, 2020

Accepted Apr 18, 2020

\section{Keywords:}

Comprehensive learning

Convergence

Distributed generation

Particle swarm optimization

Power loss

ABSTRACT

With the technological advancements, distributed generation (DG) has become a common method of overwhelming the issues like power losses and voltage drops which accompanies with the leaf of the feeders of radial distribution networks. Many researchers have used several optimization techniques and tools which could be used to locate and size the DG units in the system. Particle swarm optimization (PSO) is one of the famous optimization techniques. However, the premature convergence is identified as a fundamental adverse effect of this optimization technique. Therefore, the optimization problem can direct the objective function to a local minimum. This paper presents a variant of PSO techniques, "comprehensive learning particle swarm optimization (CLPSO)" to determine the optimal placement and sizing of the DGs, which uses a novel learning strategy whereby all other particles' historical best information and learning probability value are used to update a particle's velocity. The CLPSO particles learn from one exampler for few iterations, instead of learing from global and personal best values in every iteration in PSO and this technique retains the swarm's variability to avoid premature convergence. A detailed analysis was conducted for the IEEE 33 bus system. The comparison results have revealed a higher convergence and an accuracy than the PSO.
\end{abstract}

Copyright $(2020$ Institute of Advanced Engineering and Science. All rights reserved.

\section{Corresponding Author:}

Eshan Karunarathne,

Institute of Sustainable Energy,

University Tenaga Nasional (UNITEN),

Jalan IKRAM-UNITEN, 43000, Kajang, Selangor, Malaysia.

Email: eshkaru16@gmail.com

\section{INTRODUCTION}

The electricity system comprises electricity generation units, electricity consumption devices and a distribution grid or the distribution system where all the devices connected. The distribution system endeavors to have a smooth transportation of electricity from the generation to consumption, thus ensuring that all consumers have an agreed reliability and voltage quality. Most distribution networks are either radial or weakly meshed and it contributes a significant portion of total power losses in the whole power system due to higher load growth and the inherited high $\mathrm{X} / \mathrm{R}$ ratio. The quality of the voltage level often falls in the direction of the feeder end and it could contribute a sudden severe system collapse. Even if it is possible to eliminate such issues with the introduction of a centralized power plant, the capital and maintenance costs remain unsustainable.

Nowadays, DGs has come up as an appealing option to all the problems in distribution systems because of their benefits in terms of technical, economic and environmental [1, 2]. In [3], the DGs are classified as power generating sources that have a standard capacity of less than $50 \mathrm{MW}$, connected to 
distribution systems. The primary purpose of DGs is the energy injection and its influences on the distribution system have been studied by number of researchers [4] and some of the studies have pointed that non-optimized placement and sizing of DGs might result to increased line losses and violations in voltage statutory limits. Strategically-positioned and controlled DGs will provide several benefits, such as increased voltage profile and loadability, enhanced stability, network upgrades [5, 6] and reduced line losses [7-9]. Also, in [10], a grid connected PV system for a campus micro grid was presented.

Different kinds of optimization strategies have been used by integration of DGs in the distribution system. In [11] authors derived a collection of analytical expressions to determine the optimal size and the power factor of various types of DGs to realize the maximum loss reduction percentage and it comes under classical optimization algorithms. It does not consider convergence as a consequence of non-iterative, but in the case of complex problems analytical techniques may be unreliable due to less accuracy. Mixed Integer Linear Programming has been used in [12] to tackle the optimal size and the location of DGs for various load levels and topologies in order to minimize the annual investment and operation cost. This method will facilitate a less reliable solution through linearization and by overcoming the linearization flaw, Mixed Integer Non-Linear Programming [13] has brought a great precision. The authors in [14-18] adopted genetic algorithm to identify the optimal placement and size of DGs in different network systems. Genetic algorithms are computationally incompetent to deal with massive problems and easily achieve the state of premature convergence by trapping in to a local minima.

The Tabu search algorithm relies on adaptive and receptive memory values. In [19], an effective hybrid approach for optimum assignment of active and reactive power injection was proposed using Tabu search and genetic algorithm. Nevertheless, numerous parameters of iteration and optimization are involved, which intensify the deterioration of their computational efficiency and the performance in preparing with the DG integration. Ant colony optimization (ACO) implies the finding of shortest path to a solution through the social behavior of insects [20]. ACO is arithmetically powerful and has no any convergence issues. However, the theoretical analysis is not easy and the time taken to reach the convergence is unknown.

PSO has been tested and used by many researches for different types of problems. Authors in [21-24] used PSO variants for optimal placement and sizing of DG to improve the voltage profile and reduce the losses of the radial distribution network. PSO algorithm has the ease of implementation and enhances the quality of the optimal solution which requires fewer iterations than genetic algorithms. However, the final solution of this optimization technique may converge earlier, which is known as premature convergence and get stucked in local optima.

As already stated, almost all the evolutionary optimization techniques are the legacy of the premature convergence and wrapped up in the local optimum. Therefore, in this paper CLPSO is utilized to solve the optimal sizing of the distributed generation. This technique helps swarm stability to be retained to avoid premature convergence. Voltage stability index (VSI) is used to reduce the search space of the optimal DG integration location by removing the buses which have the index value above 0.9 .

\section{RESEARCH METHOD}

\subsection{Problem formulation}

\subsubsection{Objective function}

The main objective of allocating DGs in a distribution network is to get the maximum feasible benefits by enhancing the system's efficiency in terms of improving the power loss reduction and the voltage profile. The problem could be mathematically formulated as in (1), with an objective of minimizing the loss of real power.

$$
\text { Minimize } P_{L}=\sum_{i=1}^{N} P_{\text {loss }}=\sum_{i=1}^{N} I_{b r, i}^{2} \times R_{i} \text { for } i=1,2 . . N
$$

where $I_{b r, i}$ and $R_{i}$ is the $i^{\text {th }}$ branch current and the branch resistace respectively.

\subsubsection{Constraints}

Optimization algorithm is subjected to the constraints as defined below.

\section{A. Voltage constraint}

Absolute value of the voltage magnitude at each node must be stationed within their allowable ranges in order to maintain the system's power quality. It is defined as below.

$$
\left|V_{\text {min }}\right| \leq V_{i} \leq\left|V_{\text {max }}\right| \text { for } i=1,2 . . N
$$

where $\mathrm{N}$ is the number of buses in the system. 


\section{B. DG capacity constraint}

The connected DG unit's active and reactive power generation must be lower than the base system's active and reactive power loads. Also, it should be lower than the DG's maximum generation capability. Mathematically, this constraint was defined as follows:

$$
P_{D G, \min }<P_{D G}<P_{D G, \max }
$$

C. Thermal limit constraints

The thermal limit must not exceed its limits.

$$
S_{i} \leq S_{\text {max }} \text { for } i=1,2 \ldots N
$$

\subsection{Particle swarm optimization}

PSO algorithm is one of the evolutionary computation techniques, which is a population-based search algorithm, premised on the simulation of the social behavior of the birds within a flock, introduce originally by Kennedy and Eberhart in 1995 [25]. This stochastic algorithm works in parallel with singulars to examine appropriate regions in a multi-dimensional environment, where the optimal solution is sought. The singulars are called particles with zero mass and volume. The population is referred as the swarm and each particle in the swarm locomote towards the optimal solution with an adaptive velocity adjustment throughout the process. The velocity $V_{i}^{d}$ and the position $X_{i}^{d}$ are updated as following (5) and (6).

$$
\begin{aligned}
& V_{i(\text { updated })}^{d} \leftarrow \omega_{k} \times V_{i}^{d}+c_{1} \times \text { rand }_{i}^{d} \times\left(\text { pbest }_{i}^{d}-X_{i}^{d}\right)+c_{2} \times \operatorname{rand}_{i}^{d} \times\left(\text { gbest }^{d}-X_{i}^{d}\right) \\
& X_{i(\text { updated })}^{d} \leftarrow X_{i}^{d}+V_{i(\text { updated })}^{d}
\end{aligned}
$$

where $X_{i}=\left[X_{i}^{1}, X_{i}^{2} \ldots X_{i}^{D}\right]$ is the position of $i^{\text {th }}$ particle, $V_{i}=\left[V_{i}^{1}, V_{i}^{2} \ldots V_{i}^{D}\right]$ is the velocity of $i^{\text {th }}$ particle, Pbest $_{i}=\left[\right.$ Pbest $_{i}^{1}$, Pbest $_{i}^{2} \ldots$ Pbest $\left._{i}^{D}\right]$ is the previous personal best of $i^{\text {th }}$ particle and, gbest ${ }^{d}=$ $\left[\right.$ gbest $^{1}$, gbest $^{2}$. gbest $\left.^{D}\right]$ is the overall best of the swarm. $c_{1}$ and $c_{2}$ are the weightings of stochastic acceleration coefficients and $\operatorname{rand}_{i}^{d}$ is a random number generated in the range of $[0,1] . \omega$ is the inertia weight and it balances the global and local searching capability. All the particles attempt to improve the PSO's performance by updating their velocities and positions according to the personal best and the global best, plus varying the other parameters in different acceptable regions. However, PSO inherits the premature convergence and it's the main weakness as an optimization technique.

\subsection{Comprehensive learning particle swarm optimization}

In PSO technique, all the particles learn from their personal best and the swarm's global best simultaneously. Only the global best of the swarm could be viewed as the social learning method and a quick convergence could be expected due to having one global best. Even though the current global best is far from the optimum global best, all particles learn from the current global best. Consequently, the particles could be effortlessly trapped to a local optimal point.

In CLPSO technique, all the particles' personal best values are pooled, then two of them are used to update the personal best of one particle and it will explore more capability of un-trapping in to a local optimum point. The graphical representation of updating personal best to get rid off from local optimum is illustrated in Figure 1. The velocity updating function [26] is presented in (7).

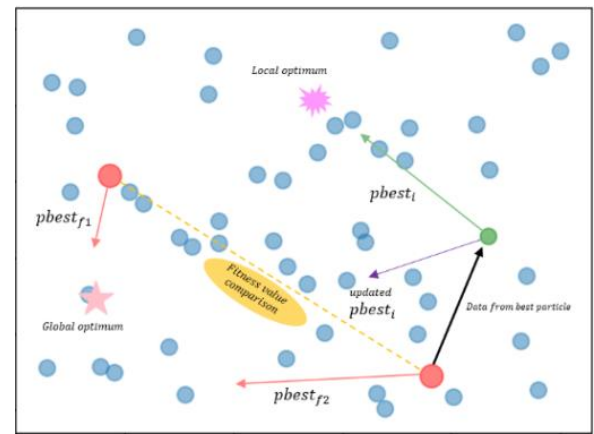

Figure 1. Graphical representation of updating personal best to get rid off from local optimum 


$$
V_{i(\text { updated })}^{d} \leftarrow \omega_{k} \times V_{i}^{d}+c \times \operatorname{rand}_{i}^{d} \times\left(\text { pbest }_{f i(d)}^{d}-X_{i}^{d}\right)
$$

where pbest $_{f i(d)}^{d}$ is the selected particle's personal best values and $f_{i(d)}=\left[f_{i}^{1}, f_{i}^{2}, \ldots, f_{i}^{D}\right]$ is particles which are the $i^{\text {th }}$ particle should follow. The velocity upgrading process verdict is determined by evaluating the randomly generated decision variable and the decision probability $(T)$. If the decision variable is larger than the decision probability, the particle learns from its own personal best and otherwise it will learn from another selected particle's personal best. The decision probability can be calculated using the (8). The decision probability for 30 particles are shown in Figure 2.

$$
T=0.05+0.45 \times\left(\frac{\exp \left[\left(\frac{(10 \times(i-1)}{p o p-1}\right)-1\right]}{\exp (10)-1}\right)
$$

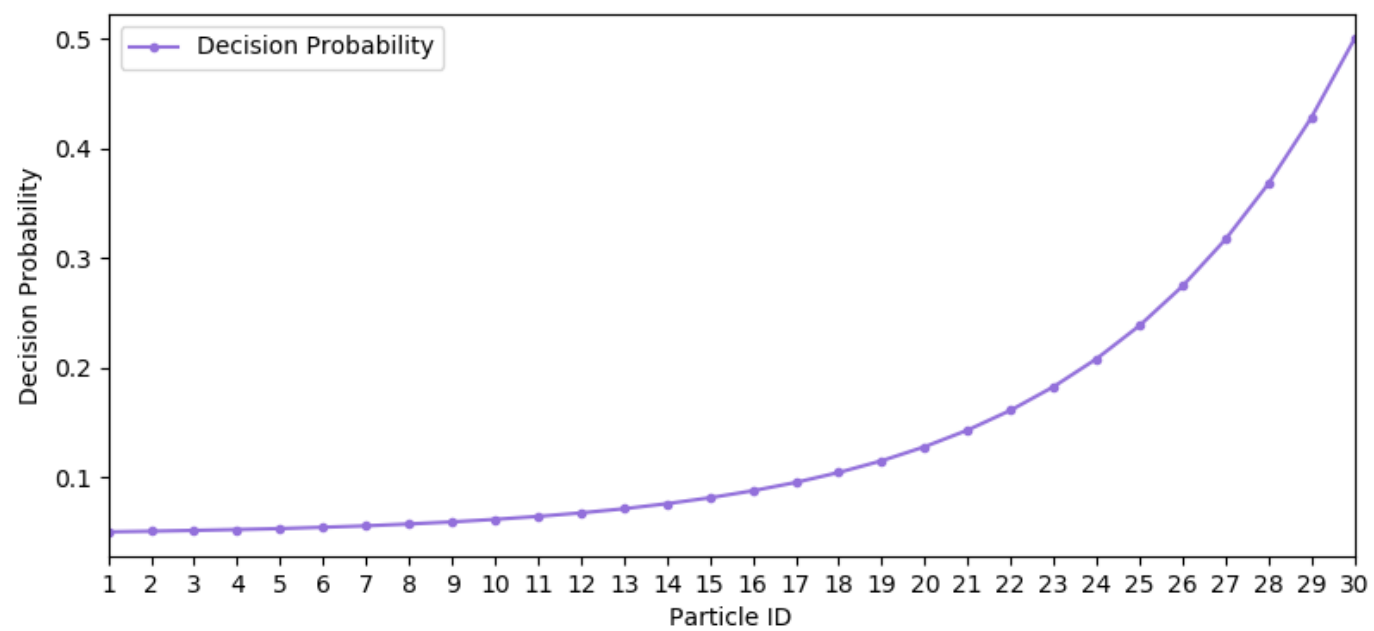

Figure 2. Decision probability of each particle in the swarm

If the decision variable is smaller than the decision probability, two random particles would be chosen from the pool and compared the fitness value of each particle's personal best. The best personal best to use in learning method would be preferred in the comprehensive learning strategy. According to the new learning, personal best particle would start its searching process in the search space. The methodology of CLPSO is illustrated in Figure 3 and a brief outline of CLSPO is given below.

Step 1 : Run the load flow without integrating DGs and record the nodal voltages line currents of the test network.

Step 2 : Initialize the parameters of CLPSO algorithm (i.e. number of iterations, number of particles, social coefficient $c$, minimum and maximum limits of inertia weight $(\omega \min \& \omega \max )$, maximum no of runs, STAG.

Step 3 : Construct randomly initialized swarm matrices for the position and velocity and run the base case power flow and compute the active power loss (objective function) using (1), nodal voltages and line currents of the network.

Step 4 : Update the position $\left(\mathrm{x}_{\mathrm{id}}^{\mathrm{k}}\right)$ and velocity $\left(\mathrm{v}_{\mathrm{id}}^{\mathrm{k}}\right)$ of the particle. Test on the network constraints consisting of velocity and position. If all the constraints are satisfied, proceed to Step 5; otherwise update the refreshing gap (STAG) by 1.

Step 5 : Identify the best personal experience (Pbest) of each particle and the best global experience (Gbest), out of every particle in the swarm.

Step 6 : Each particle has a STAG value and it is the entry-pass for comprehensive learning. If there is no improvement in objective function of each particle during STAG number of iterations, particle will enter to the comprehensive learning. 


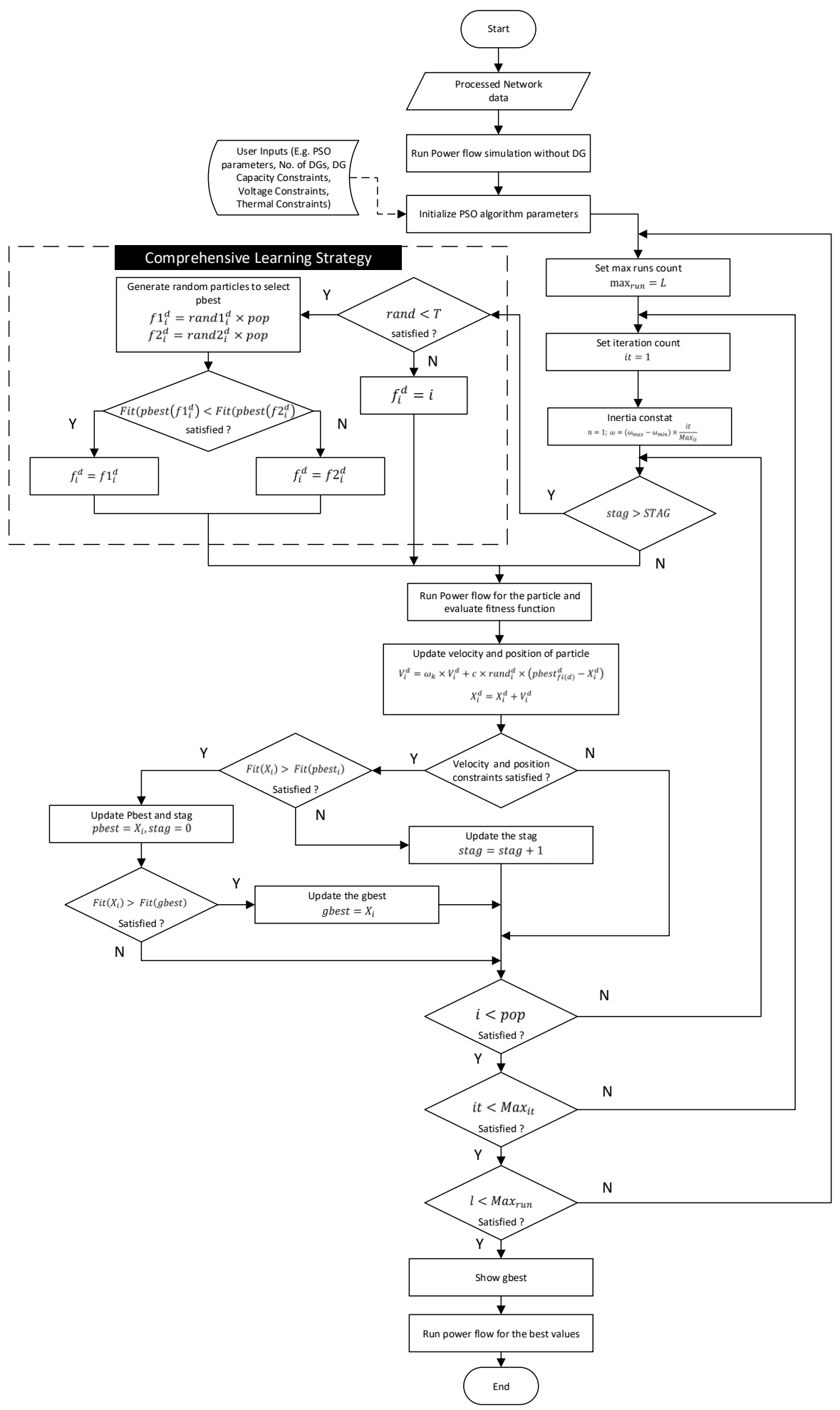

Figure 3. Flow chart of CLPSO methodology

\section{RESULTS AND DISCUSSION}

The widely used standard IEEE 33 bus system was adopted to implement CLPSO based optimal placement and sizing algorithm and simulated on MATLAB ${ }^{\mathrm{TM}}$ simulation platform. It is rated at $12.66 \mathrm{kV}$ with a total demand of 3.7MW and 2.3MVar. The single line diagram (SLD) is shown in Figure 4. All the DGs were modelled as static DGs with unity power factor. Initially, the active power integration was started by single DG and then increased up to three DGs. 
Figures 5 and 6 present the voltage profiles, convergence characteristics of fitness function value and the system power losses obtained for PSO and CLPSO algorithms respectively. In all the graphs, PSO and CLPSO results are shown in blue and orange colour respectively. The results for optimal sitting and sizing problem of distributed generation are described in Table 1.

When considering the Figure 5(a), 5(c) and 5(e), it could be seen that the voltage profiles of CLPSO were improving better than PSO. However, a significant improvement could be seen with the increment in number of DGs. The Figures 5(b), 5(d) and 5(f) present the convergence characteristics of fitness function, which evaluate the speed of convergence of the algorithm with different number of DGs. It was noticed that, in both the iterations and fitness function value, the PSO algorithm was converged before CLPSO algorithm. That is, CLPSO algorithm eliminates the premature convergence, which inherits by PSO algorithm.

The total active power loss reduction for CLPSO and PSO is shown in Figure 6. It could be observed that CLPSO has gained more loss reduction than PSO. The two algorithms were performed up to 10 runs and the best case was selected. Out of the 10 runs, the maximum (worst), the minimum (best) and the average of the objective functions to improve loss reduction in test network are illustrated and compared in Figure 7. The best and the worst are from the CLPSO and PSO respectively. Looking at the standard deviation results of the total active power loss of each algorithm, it reveals that the value for CLPSO is less than PSO. This is an indication of the uniformity of the output of CLPSO and the less uniformity of PSO.

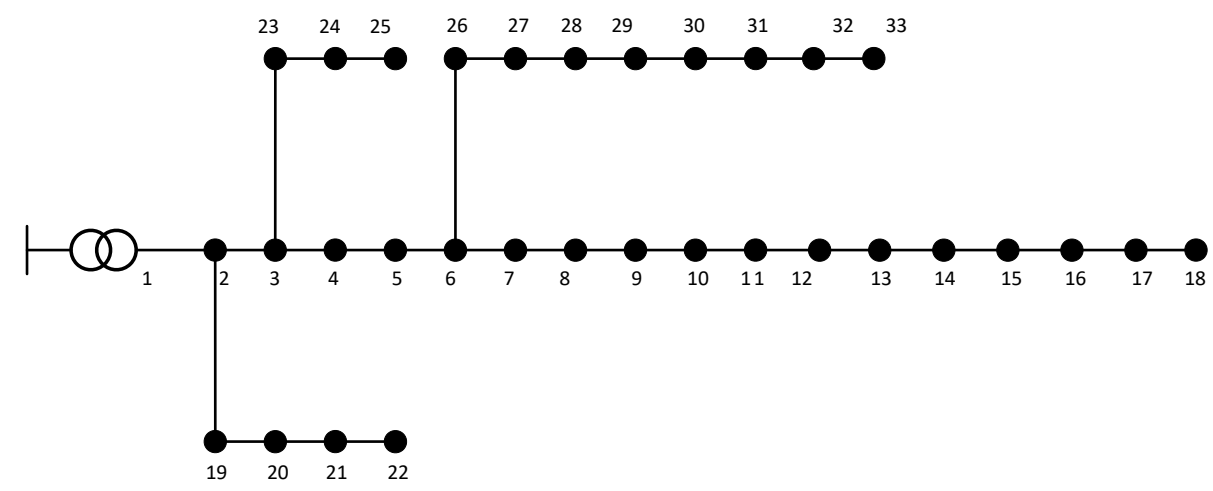

Figure 4. SLD of IEEE 33 bus system

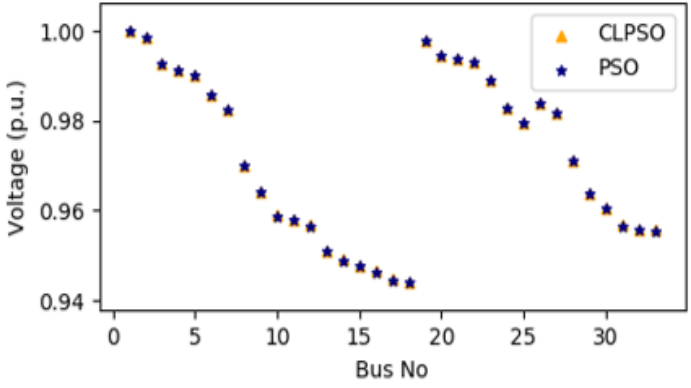

(a) 1 DG Voltage profile

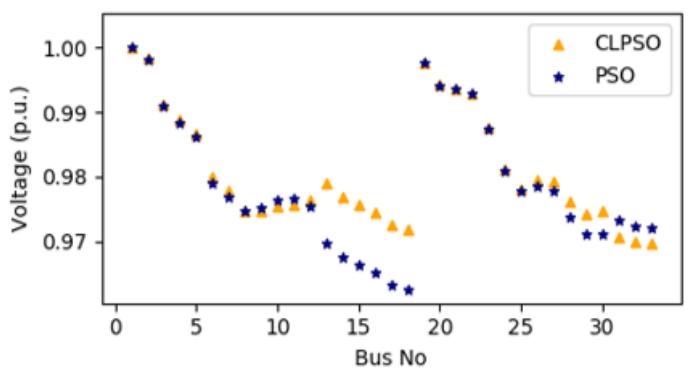

(c) 2 DGs voltage profile

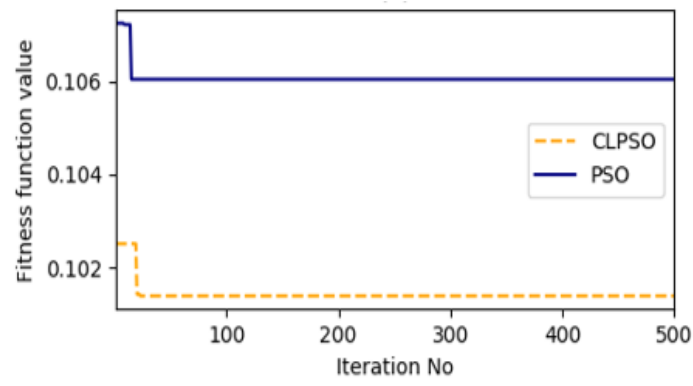

(b) 1 DG convergence characteristics

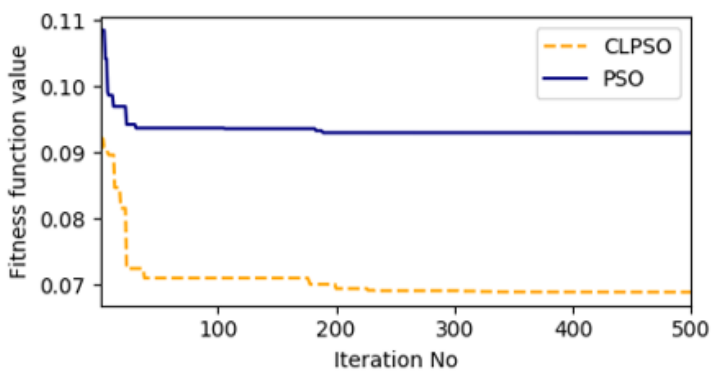

(d) 2 DGs convergence characteristics 


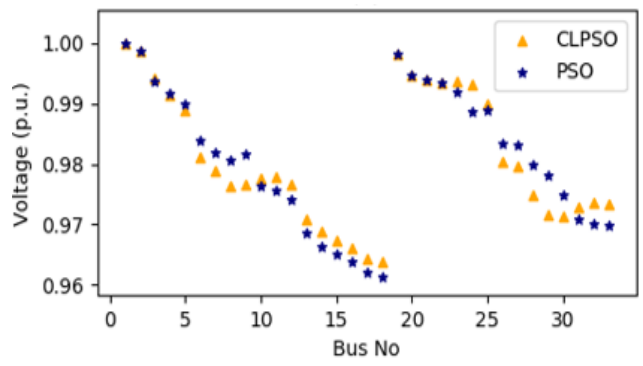

(e) 3 DGs voltage profile

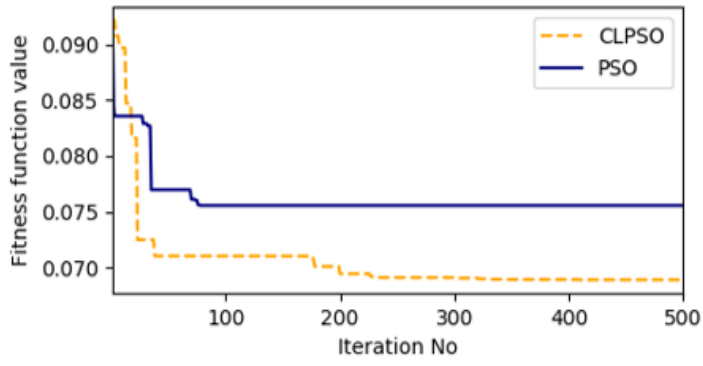

(f) 3 DGs convergence characteristics

Figure 5. Voltage variation and convergence characteristics of CLPSO and PSO

Table 1. Performance analysis of the IEEE 33 bus system after DG installation

\begin{tabular}{|c|c|c|c|c|c|c|c|c|c|}
\hline Algorithm & $\begin{array}{c}1^{\text {st }} \mathrm{DG} \\
\text { Location }\end{array}$ & $\begin{array}{c}1^{\text {st }} \text { DG } \\
\text { Size } \\
(\mathrm{MW})\end{array}$ & $\begin{array}{l}2^{\text {nd }} \mathrm{DG} \\
\text { Location }\end{array}$ & $\begin{array}{c}2^{\text {nd }} \text { DG } \\
\text { Size } \\
(\mathrm{MW}) \\
\end{array}$ & $\begin{array}{l}3^{\text {rd }} \mathrm{DG} \\
\text { Location }\end{array}$ & $\begin{array}{l}3^{\text {rd }} \text { DG } \\
\text { Size } \\
(\mathrm{MW})\end{array}$ & $\begin{array}{l}P_{\text {Loss }} \\
(\mathrm{kW})\end{array}$ & $\begin{array}{c}\text { QLoss } \\
\text { (kVar) }\end{array}$ & $\begin{array}{c}\mathrm{P}_{\text {Loss }} \\
\text { Reduction } \\
(\%)\end{array}$ \\
\hline Base Case & - & - & - & - & - & - & 210.0 & 143.0 & - \\
\hline \multirow[t]{3}{*}{ PSO } & 6 & 2.42 & - & - & - & - & 102.330 & 74.995 & 51.27 \\
\hline & 11 & 0.96 & 31 & 0.95 & - & - & 82.995 & 56.690 & 60.49 \\
\hline & 29 & 1.08 & 25 & 5.85 & 9 & 1.04 & 73.630 & 50.600 & 64.94 \\
\hline \multirow[t]{3}{*}{ CLSPO } & 6 & 2.43 & - & - & - & - & 102.120 & 75.000 & 51.40 \\
\hline & 30 & 1.10 & 13 & 0.89 & - & - & 81.720 & 55.975 & 61.10 \\
\hline & 11 & 0.93 & 32 & 5.85 & 24 & 1.05 & 70.300 & 48.775 & 66.54 \\
\hline
\end{tabular}

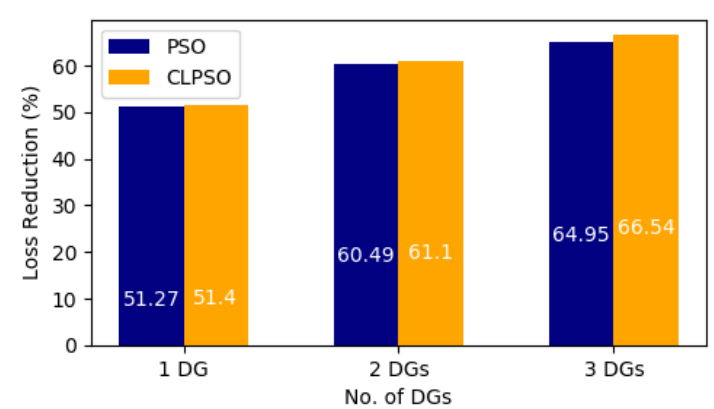

Figure 6. Loss reduction of the sytem

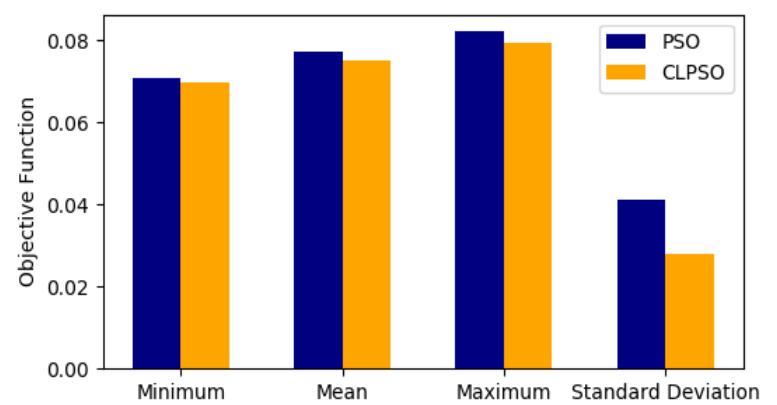

Figure 7. Statistical parametrs of algorithm results

\section{CONCLUSION}

In this paper, CLPSO technique is utilized to determine the optimal placement and sizing of the DGs, which uses a novel learning strategy, as CLPSO can eliminate the premature convergence of the PSO technique. It uses all the particles' historical personal best values to update the velocity component of each particle. The simulation results show that, while both approaches have chosen almost the same locations for the DG integration, CLPSO is performing better in maximizing loss reduction compared to PSO. They are $66.54 \%$ in CLPSO and $64.95 \%$ in PSO with three DGs. Moreover, all the CLPSO simulations converge after the PSO simulatons and could be introduced as execlusion of premature convergence. The obtained standard deviation for CLPSO is less than the PSO and it points out the quality and the uniformity of the results obtained in all the runs. Finally, the overall paper presents the productiveness of CLPSO in optimal placement and sizing of DGs than the PSO.

\section{ACKNOWLEDGEMENTS}

The authors would like to thank the Ministry of Education (MOE), Malaysia, for funding this research under a FRGS research grant (20180117FRGS). 


\section{REFERENCES}

[1] P. Chiradeja and R. Ramakumar, "An approach to quantify the technical benefits of distributed generation," IEEE Transactions on Energy Conversion, vol. 19, no. 4, pp. 764-773, 2004.

[2] G. Pepermans, J. Driesen, D. Haeseldonckx, R. Belmans, and W. D’haeseleer, "Distributed generation: Definition, benefits and issues," Energy Policy, vol. 33, no. 6, pp. 787-798, 2005.

[3] N. Jenkins, J. B. Ekanayake, and G. Strbac, "Distributed generation,” IET, 2010.

[4] G. Antonova, M. Nardi, A. Scott, and M. Pesin, "Distributed generation and its impact on power grids and microgrids protection," 2012 65th Annual Conference for Protective Relay Engineers, pp. 152-161, 2012.

[5] M. Manfren, P. Caputo, and G. Costa, "Paradigm shift in urban energy systems through distributed generation: Methods and models," Applied Energy, vol. 88, no. 4, pp. 1032-1048, 2011.

[6] G. C. Bakos, "Distributed power generation: A case study of small scale PV power plant in Greece," Applied Energy, vol. 86, no. 9, pp. 1757-1766, 2009.

[7] T. Niknam, S. I. Taheri, J. Aghaei, S. Tabatabaei, and M. Nayeripour, "A modified honey bee mating optimization algorithm for multiobjective placement of renewable energy resources," Applied Energy, vol. 88, no. 12, pp. 4817-4830, 2011.

[8] T. Niknam, "A new HBMO algorithm for multiobjective daily Volt/Var control in distribution systems considering Distributed Generators," Applied Energy, vol. 88, no. 3, pp. 778-788, 2011.

[9] M. Martinez-Rojas, A. Sumper, O. Gomis-Bellmunt, and A. Sudrià-Andreu, "Reactive power dispatch in wind farms using particle swarm optimization technique and feasible solutions search," Applied Energy, vol. 88, no. 12, pp. 4678-4686, 2011.

[10] M. Reyasudin Basir Khan, J. Pasupuleti, J. Al-Fattah, and M. Tahmasebi, "Optimal grid-connected PV system for a campus microgrid," Indonesian Journal of Electrical Engineering and Computer Science, vol. 12, no. 3, pp. 899-906, 2018.

[11] D. Q. Hung, N. Mithulananthan, and R. C. Bansal, "Analytical expressions for DG allocation in primary distribution networks," IEEE Transactions on Energy Conversion, vol. 25, no. 3, pp. 814-820, 2010.

[12] A. C. Rueda-Medina, J. F. Franco, M. J. Rider, A. Padilha-Feltrin, and R. Romero, "A mixed-integer linear programming approach for optimal type, size and allocation of distributed generation in radial distribution systems," Electric Power Systems Research, vol. 97, pp. 133-143, 2013.

[13] S. Kaur, G. Kumbhar, and J. Sharma, "A MINLP technique for optimal placement of multiple DG units in distribution systems," International Journal of Electrical Power and Energy Systems, vol. 63, pp. 609-617, 2014.

[14] A. A. Abou El-Ela, S. M. Allam, and M. M. Shatla, "Maximal optimal benefits of distributed generation using genetic algorithms," Electric Power Systems Research, vol. 80, no. 7, pp. 869-877, 2010.

[15] S. Biswas, S. K. Goswami, and A. Chatterjee, "Optimum distributed generation placement with voltage sag effect minimization," Energy Conversion and Management, vol. 53, no. 1, pp. 163-174, 2012.

[16] T. Jin, Y. Tian, C. W. Zhang, and D. W. Coit, "Multicriteria planning for distributed wind generation under strategic maintenance," IEEE Transactions on Power Delivery, vol. 28, no. 1, pp. 357-367, 2013.

[17] P. Dehghanian, S. H. Hosseini, M. Moeini-Aghtaie, and A. Arabali, "Optimal siting of DG units in power systems from a probabilistic multi-objective optimization perspective," International Journal of Electrical Power and Energy Systems, vol. 51, pp. 14-26, 2013.

[18] F. Ud Din, A. Ahmad, H. Ullah, A. Khan, T. Umer, and S. Wan, "Efficient sizing and placement of distributed generators in cyber-physical power systems," Journal of Systems Architecture, vol. 97, pp. 197-207, 2019.

[19] B. R. Pereira, G. R. M. Martins Da Costa, J. Contreras, and J. R. S. Mantovani, "Optimal Distributed Generation and Reactive Power Allocation in Electrical Distribution Systems," IEEE Transactions on Sustainable Energy, vol. 7, no. 3, pp. 975-984, 2016.

[20] W. Dong, Y. Li, and J. Xiang, "Optimal sizing of a stand-alone hybrid power system based on battery/hydrogen with an improved ant colony optimization," Energies, vol. 9, p. 785, 2016.

[21] J. J. Jamian, M. W. Mustafa, H. Mokhlis, and M. A. Baharudin, "A New Particle Swarm Optimization Technique in Optimizing Size of Distributed Generation," International Journal of Electrical and Computer Engineering (IJECE), vol. 2, no. 1, pp. 137-146, 2012.

[22] J. J. Jamian, M. W. Mustafa, H. Mokhlis, and M. A. Baharudin, "Implimentation of Evolutionary Particle Swarm Optimization in Distributed Generation Sizing," International Journal of Electrical and Computer Engineering (IJECE), vol. 2, no. 1, pp. 137-146, 2012.

[23] P. S. Meera and S. Hemamalini, "Optimal siting of distributed generators in a distribution network using artificial immune system," International Journal of Electrical and Computer Engineering, vol. 7, no. 2, pp. 641-649, 2017.

[24] K. Bhumkittipich and W. Phuangpornpitak, "Optimal placement and sizing of distributed generation for power loss reduction using particle swarm optimization," Energy Procedia, vol. 34, pp. 307-317, 2013.

[25] J. Kennedy and R. Eberhart, "Particle swarm optimization," Proceedings of ICNN'95-International Conference on Neural Networks, Perth, WA, Australia, vol. 4, pp. 1942-1948, 1995.

[26] J. J. Liang, A. K. Qin, S. Member, P. N. Suganthan, S. Member, and S. Baskar, "Comprehensive learning PSO for global optimization of multimodal functions," IEEE transactions on evolutionary computation, vol. 10, no. 3, pp. 281-295, 2006. 